J Proteome Res. 2016 August 05; 15(8): 2356-2365. doi:10.1021/acs.jproteome.5b00938.

\title{
Neisseria meningitidis lacking the major porins PorA and PorB are viable and modulate apoptosis and the oxidative burst of neutrophils
}

\author{
lan R. Peak ${ }^{1,2,+}$, Adrienne Chen ${ }^{3,+\&}$, Freda E.-C. Jen², Courtney Jennings ${ }^{2}$, Benjamin L. \\ Schulz ${ }^{4}$, Nigel J. Saunders ${ }^{5}$, Arshad Khan ${ }^{5}$, H. Steven Seifert ${ }^{3,{ }^{*}}$, and Michael P. Jennings ${ }^{2},{ }^{*}$ \\ ${ }^{1}$ School of Medical Science, Griffith University, Southport, QLD 4222, Australia \\ 2Institute for Glycomics, Gold Coast Campus, Griffith University, Southport, QLD 4222, Australia \\ ${ }^{3}$ Department of Microbiology-Immunology, Northwestern University's Feinberg School of \\ Medicine, 303 East Chicago Avenue, Chicago, IL 60611, USA \\ ${ }^{4}$ Australian Infectious Diseases Research Centre, School of Chemistry and Molecular \\ Biosciences, The University of Queensland, St. Lucia, Brisbane, QLD 4072, Australia \\ ${ }^{5}$ Centre for Systems and Synthetic Biology, Brunel University, Uxbridge, Middlesex, UK
}

\section{Abstract}

The bacterial pathogen Neisseria meningitidis expresses two major outer-membrane porins. PorA expression is subject to phase-variation (high frequency, random, on-off switching) and both PorA and PorB are antigenically variable between strains. PorA expression is variable and not correlated with meningococcal colonisation or invasive disease, whereas all naturally-occurring strains express PorB suggesting strong selection for expression. We have generated $N$. meningitidis strains lacking expression of both major porins, demonstrating that they are dispensable for bacterial growth in vitro. The por $A B$ mutant strain has an exponential growth rate similar to the parental strain, as do the single por $A$ or por $B$ mutants, but the por $A B$ mutant strain does not reach the same cell density in stationary phase. Proteomic analysis suggests that the double mutant strain exhibits compensatory expression changes in proteins associated with cellular redox state, energy/ nutrient metabolism, and membrane stability. On solid media, there is obvious growth impairment that is rescued by addition of blood or serum from mammalian species, particularly heme. These porin mutants are not impaired in their capacity to inhibit both staurosporine-induced apoptosis and a phorbol 12-myristate 13-acetate -induced oxidative burst in human neutrophils suggesting that the porins are not the only bacterial factors that can modulate these processes in host cells.

\footnotetext{
"Corresponding authors: h-seifert@ @orthwestern.edu Telephone: +1 312-503-9788, m.jennings@ griffith.edu.au Telephone: +61 7 55527050.

${ }^{+}$IRP and AC contributed equally to this study

${ }^{\&}$ Current Address: Department of Ophthalmology and Visual Sciences, University of Michigan, 1000 Wall Street, Ann Arbor, MI 48105, USA

This material is available free of charge via the Internet at http://pubs.acs.org
} 


\section{Keywords}

Neisseria meningitidis; Porins; PorA; PorB

\section{Introduction}

The pathogenic Neisseria, $N$. meningitidis and $N$. gonorrhoeae cause meningococcal disease and gonorrhoea, respectively. They are host-adapted organisms, residing only in humans. They must acquire all necessary nutrients from the host environment. Although closely related, there are significant differences between $N$. meningitidis and $N$. gonorrhoeae. One significant difference is that $N$. meningitidis expresses two major porins, PorA and PorB, whereas $N$. gonorrhoeae expresses a single major porin, PIB (most similar to PorB).

Bacterial porins are integral major outer membrane proteins that allow small molecules to transit the outer membrane into the periplasm. PorA and PorB of $N$. meningitidis are trimeric voltage-gated pores that mediate ion exchange between the organism and its environment ${ }^{1}$. PorA is cation selective ${ }^{2}$, and different PorA proteins differ in their cation selectivity, perhaps as the result of changes in net charge of an extracellular loop ${ }^{3}$. PorB also possesses cation and anion translocation pathways ${ }^{4-5}$, and is reported to be more selective for anions $\left(\mathrm{Cl}^{-}\right)$over cations $\left(\mathrm{Na}^{+}\right)^{5}$

A pseudogene ortholog of the porA gene of $N$. meningitidis is present in $N$. gonorrhoeae that is not expressed as a result of accumulated mutations, although rare strains of $N$. gonorrhoeae contain a meningococcal porA gene ${ }^{6}$. The PorA protein of $N$. meningitidis displays phase-variable expression (high frequency reversible on/off switching) ${ }^{7}$. Although most $N$. meningitidis strains express PorA, there are occasional reports of strains lacking PorA causing disease in humans ${ }^{8-9}$. There have been no reports of natural isolates of $N$. meningitidis or $N$. gonorrhoeae lacking PorB/PIB. Efforts to produce $N$. gonorrhoeae lacking PorB expression have been unsuccessful ${ }^{10}$. PorB expression has been experimentally abolished in $N$. meningitidis ${ }^{2}$, but this strain is reported to exhibit slightly reduced growth rates in vitro, whereas PorA mutants appear not to have growth defects ${ }^{2}$. PorA-dependent uptake of sugars is size dependent, with demonstrated transport of arabinose, glucose, and nacetylglucosamine ${ }^{3}$. This is similar to the uptake of sugars by PorB using liposomes, with translocation of (in order of fastest translocation): glucose>galactose>arabinose ${ }^{11}$. PorB also has a minor role in antibiotic influx, where loss of this protein decreases susceptibility to cefsulodin, tetracycline ${ }^{2}$, doxycycline, ciprofloxacin, cefotaxime, ceftazidime, and cephalothin $^{12}$. In contrast, PorA deletion has no effect on antimicrobial susceptibility 2,12 . Taken together, both pathogens require PorB/PIB expression, but PorA expression by $N$. meningitidis is advantageous but not essential for human colonisation or disease.

In addition to their functions as voltage-gated pores, porins have also been shown to play additional roles in Neisseria biology. PorB purified from Neisseria gonorrhoeae was first proposed to induce apoptosis when HeLa and other cells were exposed to concentrations of $10 \mu \mathrm{g} / \mathrm{mL}$ purified PorB ${ }^{13}$. Purified gonococcal PorB, or PorB transferred into cells during bacterial infection by unknown mechanisms, was shown to target to the mitochondria and induce apoptosis ${ }^{14}$. Conversely, other studies have shown that purified meningococcal PorB 
interacts with Jurkat cell mitochondria to protect cells from apoptosis ${ }^{15}$. Furthermore, following infection of HeLa cells with $N$. meningitidis, PorB was shown to be physically associated with mitochondria, but RmpM, another major Neisseria protein, was not ${ }^{16}$. It was inferred from these observations that the anti-apoptotic effect is PorB-dependent. The PorBdependent anti-apoptotic effect of $N$. meningitidis infection on macrophage cells was further found to be dependent on the presence of nitrosative stress ${ }^{17}$. More recently, Chen and Seifert made a series of $N$. gonorrhoeae PorB mutant strains, demonstrating that almost all PorB amino acids are mutable ${ }^{18}$. A subset of these mutant strains was tested for their ability to protect against apoptosis, and none of the strains were altered in their capacity to inhibit apoptosis compared to the parental strain ${ }^{18-19}$.

In this study, we generated meningococcal mutant strains lacking PorA, PorB or both PorA and PorB expression. We examined how depletion of both major porins affected growth rate, undertook proteomic and genomic analysis of these strains to assess compensatory regulatory or genetic changes, and examined their capacity to inhibit the proposed, porindependent PMN apoptosis and the oxidative burst in vitro.

\section{Material and Methods}

Bacterial strains and growth conditions: Escherichia coli was routinely grown on LB medium at $37^{\circ} \mathrm{C}$. Antibiotics were added as necessary at $100 \mu \mathrm{g} / \mathrm{mL}$ (ampicillin), $10 \mu \mathrm{g} / \mathrm{mL}$ (tetracycline, chloramphenicol). N. meningitidis was routinely grown on BHI agar with 5\% defibrinated horse blood, or with added Levinthal's supplement (BHI and defibrinated horse blood equal volume, autoclaved at $121{ }^{\circ} \mathrm{C}$, cooled and centrifuged, and added at $10 \% \mathrm{v} / \mathrm{v}$ to BHI). Antibiotics were added as necessary at $5 \mu \mathrm{g} / \mathrm{mL}$ (tetracycline), and $3-5 \mu \mathrm{g} / \mathrm{mL}$ (chloramphenicol). For experiments investigating growth of mutant strains on different media, $N$. meningitidis was cultured on gonococcal medium base (GCB; Difco) agar plus various supplements. These supplements included Kellogg's supplements ${ }^{20}$, IsoVitalex (Becton Dickinson), defibrinated animal blood (Lampire Biologicals), animal serum (Lampire Biologicals), $10 \mu \mathrm{M}$ bovin hemin (Sigma), and 5\% human hemoglobin (Sigma). Animal serum was also treated with either 5\% Chelex 100 (BioRad), $500 \mathrm{ug} / \mathrm{ml}$ proteinase $\mathrm{K}$ (Invitrogen), $10 \mathrm{ug} / \mathrm{ml}$ DNase (Worthington), $10 \mathrm{ug} / \mathrm{ml}$ RNase (Sigma), or $5 \mathrm{mM} \mathrm{PMSF}$ (Sigma) before being added to the GCB. Strains were cultured on agar medium for 16 to 18 hours at $37^{\circ} \mathrm{C}$ with $5 \% \mathrm{CO}_{2}$.

\section{Growth curves}

N. meningitidis MC58 and derivatives from 16-18 hours growth on solid media were subcultured for 3-4 hours on solid media, resuspended to OD A600=1, diluted 1:5 into $1 \mathrm{ml}$ Levinthal's supplemented BHI in triplicate into individual sealed $2 \mathrm{~mL}$ cuvettes, and then incubated with shaking at $37{ }^{\circ} \mathrm{C}$. Growth was monitored at hourly intervals. The experiment was repeated twice. Exponential growth phase was defined as between $120 \mathrm{~min}$ and 180 min. Samples at OD A600=1 were analysed by coomassie staining and Western blotting, PorA expression was monitored with anti P1.7 mAb MN14C11.6, and PorB with anti P3.15 $\mathrm{mAb} 2-\mathrm{P}-15$ (obtained from NIBSC, UK). Samples at OD A600 $=1$ were serially diluted and colonies counted after 30 hours growth on Levinthal's supplemented BHI agar. 


\section{Generation of plasmid constructs}

The porA gene and flanking sequence was amplified from MC58 genomic DNA using primers PorAFor 1 ( $5^{\prime}$-GTTTCGGTCGTTTCCGATAA-3') and PorAR1 (5' TTGAAACCCTGACCCTCTG- $3^{\prime}$ ) and cloned into pGEMTeasy (Promega), to generate pPorA (fig 1A). Inverse PCR on pPorA using primers DelPorA-UP $5^{\prime}$-TCGCATATC GGCTTCCTTTTGTAAATTTGA-3' ${ }^{\prime}$ and DelPorA-DOWN $5^{\prime}$-TCC GTC GGT TTG CGC CAC AAA TTC- $3^{\prime}$ was performed to delete the porA ORF and to insert a Smal site. The tetracycline resistance cassette from $\mathrm{pGemTetMB}^{21}$ was cloned into the Smal site of pPorA to generate pPorA::Tet (fig 1C). After amplification and cloning of porB from MC58 genomic DNA with PorBF1 (5' -GCCCTCCAATACCCTCCCGAGTA-3') and PorBR1 (5' TGCCGTCTGAAGACTTCAGACGGCCGACAGGCTTTTTGTTGATACC-3') (see fig. 1C), a $B g I I$ site was introduced by PCR. The chloramphenicol resistance determinant was amplified from pCmGFP ${ }^{22}$ with primers including BamHI sites (Cat5' Bam: $5^{\prime}$ -

GTGGATCCACACAATCTGCCCTTT-3', Cat3'Bam: 5' -

GGATCCGCACCAATAACTGCCTTA- $3^{\prime}$ and the cat gene was cloned into BgIII digested pPorB to generate pPorB:Cat (fig 1D), and plasmid sequenced to confirm site of cat insertion. RNA was extracted from bacteria grown in Levinthal's supplemented BHI liquid media (grown to A600 OD1) using QIAGEN RNeasy kit, prior to conversion to cDNA, and quantitative real-time PCR, using primers Nm16S_For : $5^{\prime}$ -

CGTGGGTGCGAGCGTTAATC-3', Nm16S_Rev: 5' -

CTGCCTTCGCCATCGGTATTCCT-3', PorA_RT_For: 5' TAAGGGGAGTGAGGATTTGGGC-3', PorA_RT_Rev: 5' ATCAATGGCTTGGCTGGCATCG-3', PorB_RT_For: 5' TCAAACCGAAGTTGCCGCTACC-3' ${ }^{\prime}$, and PorB_RT_Rev: 5' TTGGAGAAGTCGTATTCCGCACC- $3^{\prime}$. Abundance of transcripts for por $A$ and $p o r B$ was calculated for strains MC58, $58 \Delta \mathrm{A}$ and $58 \Delta \mathrm{B}$ relative to 16 sRNA.

\section{Protein analysis}

Bacteria were harvested from liquid media growth at OD A600 $=1$ and resuspended in 10 $\mathrm{mM}$ Tris $\mathrm{pH}$ 8.0. After separation on 4-12\% Bis-Tris acrylamide gels, proteins were analysed using coomassie staining or western blotting. PorA and PorB expression was confirmed using goat polyclonal anti-PorA (sc-17396, Santa Cruz Biotechhnology), or murine mAb 8B5-5-G9 (anti-PorB, P3.15, obtained from NIBSC, UK). Alkalinephosphatase-conjugated donkey anti-goat, and goat anti-mouse antibodies (Sigma-Aldrich) were used with colorimetric reagents to detect binding. For protein identification of bands excised from coomassie-stained gels, outer-membrane proteins were enriched using $1 \%$ sarkosyl detergent extraction, and LC-MS/MS was carried out as previously described ${ }^{23}$

\section{Mass spectrometry (MS)}

For SWATH-MS, 3-5 colonies were harvested into $300 \mu \mathrm{L} 6 \mathrm{M}$ guanidinium chloride, 50 $\mathrm{mM}$ Tris- $\mathrm{HCl} \mathrm{pH} \mathrm{8,} 10 \mathrm{mM}$ DTT and incubated at $30^{\circ} \mathrm{C}$ for $30 \mathrm{~min}$. Cysteines were alkylated by addition of acrylamide to $25 \mathrm{mM}$ and incubation at $30^{\circ} \mathrm{C}$ for 1 hour, followed by further addition of DTT to $5 \mathrm{mM}$. Proteins were precipitated by addition of $1.2 \mathrm{~mL} \mathrm{1:1}$ methanol:acetone, incubation at $-20^{\circ} \mathrm{C}$ for 16 hours, and centrifugation at $18,000 \mathrm{rcf}$ for 10 
min. The air-dried protein pellet was resuspended in $100 \mu \mathrm{L} 50 \mathrm{mM}$ Tris- $\mathrm{HCl} \mathrm{pH} 8$ with 1 $\mu \mathrm{g}$ trypsin (proteomics grade, Sigma-Aldrich) and incubated at $37^{\circ} \mathrm{C}$ for 16 hours. Peptides were desalted with C18 ZipTips (Millipore). Proteins were identified by information dependent acquisition LC-ESI-MS/MS analysis performed as previously described ${ }^{24}$ using a Prominence nanoLC system (Shimadzu) and TripleTof 5600 mass spectrometer with a Nanospray III interface (AB SCIEX). Briefly, approximately $2 \mu \mathrm{g}$ peptides were desalted on an Aglient $\mathrm{C} 18$ trap and then separated on a Vydac EVEREST reversed-phase C18 HPLC column at a flow rate of $1 \mu \mathrm{L} / \mathrm{min}$. Separation used a gradient of $10-60 \%$ buffer B over 45 min, with buffer A ( $1 \%$ acetonitrile and $0.1 \%$ formic acid) and buffer B (80\% acetonitrile and $0.1 \%$ formic acid). An MS TOF scan was performed from an $m / z$ of $350-1800$ for $0.5 \mathrm{~s}$ followed by information dependent acquisition of MS/MS of the top 20 peptides from $\mathrm{m} / \mathrm{z}$ 40-1800 for $0.05 \mathrm{~s}$ per spectrum, with automated CE selection. Identical LC conditions were used for SWATH-MS ( Sequential Window Accquisition of all THeoretical Mass Spectra) ${ }^{25}$. SWATH-MS of triplicate biological replicates was performed as previously described ${ }^{26}$ with an MS-TOF scan from an $m / z$ of 350-1800 for $0.05 \mathrm{~s}$, followed by high sensitivity information-independent acquisition with $26 \mathrm{~m} / z$ isolation windows with $1 \mathrm{~m} / z$ window overlap each for $0.1 \mathrm{~s}$ across an $\mathrm{m} / \mathrm{z}$ range of $400-1250$. Collision energy was automatically assigned by Analyst software (AB SCIEX) based on $\mathrm{m} / \mathrm{z}$ window ranges. Proteins were identified essentially as described ${ }^{27}$ using ProteinPilot (AB SCIEX), searching a database with all predicted $N$. meningitidis MC58 proteins and common contaminants with standard settings: Sample type, identification; Cysteine alkylation, acrylamide; ID focus, biological modifications; Enzyme, Trypsin, Search effort, thorough ID. False discovery rate analysis was performed on all searches. ProteinPilot search results were used as ion libraries for SWATH analyses. The abundance of proteins was measured automatically using PeakView (AB SCIEX) with standard settings. Comparison of protein relative abundance was performed based on protein intensities ${ }^{26}$, or ion intensities using a linear mixed-effects model with the MSstats package in $\mathrm{R}^{28}$. Proteins with greater than $30 \%$ changes in abundance and with adjusted P-values $<0.05$ were considered significant.

\section{Genome sequencing and assembly}

The genome assembly was carried out using the Spades Genome Assembler in pair end mode with - careful preset ${ }^{29}$. BayesHammer was used for read (150 bp) error correction prior to assembly with default parameters. In the Spades genome assembly module, k-mer lengths of 21, 33, 55 and 77 were used to build an iterative genome assembly. Post processing of assembled contigs/scaffolds for mismatch correction was done with Burrows Wheeler Aligner (BWA tool) ${ }^{30}$. For SNP analysis, paired-end reads were mapped against the N. meningitidis MC58 reference genome (NC_003112.2) using Bowtie2 with -sensitive preset. MarkDuplicates from Picard tool set was used to remove duplicate reads and SAMtools for transforming data into mpileup format. Single nucleotide polymorphisms were then called using VarScan 2.3.6 $6^{30-31}$ with only those reported that had evidence from reads in both orientations.

\section{Eukaryotic cell assays}

The ability of $N$. meningitidis porin mutants to inhibit apoptosis and ROS production was determined using HL-60 cells differentiated down the granulocytic pathway as previously 
described ${ }^{[17]}$. HL-60 cells were differentiated in $0.7 \%$ dimethylformamide (Sigma) for a period of 5 days, after which cells were infected with $N$. meningitidis strains. For the apoptosis inhibition assays, differentiated HL-60 cells were infected at a multiplicity of infection (MOI) of 50 for 3 hours, followed by treatment of cells with $1 \mu \mathrm{M}$ staurosporine for 3 hours to induce apoptosis. Cells were washed with phosphate-buffered saline (PBS) before being treated with $50 \mu \mathrm{L}$ cell lysis buffer (BD Pharmingen) to harvest cell lysates. To measure caspase- 3 activity in the lysates, $5 \mu \mathrm{L}$ reconstituted caspase- 3 substrate ( $\mathrm{N}$-acetylAsp-Glu-Val-Asp-7-amino-4-methylcoumarin [Ac-DEVD-AMC]; BD Pharmingen) at a concentration of $1 \mathrm{mg} / \mathrm{ml}$ was incubated with assay buffer and $25 \mu \mathrm{L}$ cell lysates for $60 \mathrm{~min}$ at $37^{\circ} \mathrm{C}$. 7-Amino-4-methylcoumarin (AMC) fluorescence was measured using an excitation wavelength of $380 \mathrm{~nm}$, an emission wavelength of $440 \mathrm{~nm}$, and a SpectraMax M5 plate reader (Molecular Devices). Luminol-dependent chemiluminescence (LDCL) assays were performed to examine ROS production by infected HL-60 cells ${ }^{[17]}$. Assays were carried out in a total volume of $0.2 \mathrm{ml} \mathrm{PBS}$ supplemented with $0.9 \mathrm{mM} \mathrm{CaCl}_{2}, 0.5 \mathrm{mM} \mathrm{MgCl}_{2}$, and 7.5 $\mathrm{mM}$ glucose (PBSG) in black-bottom 96-well plates (Nunc). HL-60 cells were resuspended at a concentration of $4 \times 10^{7}$ cells $/ \mathrm{ml}$, and $10^{6}$ cells were seeded in the presence of $100 \mu \mathrm{M}$ luminol. The cells were then stimulated with $100 \mathrm{ng} / \mathrm{ml}$ phorbol 12-myristate 13-acetate (PMA) and/or $N$. meningitidis strains that had been grown overnight on $\mathrm{GCB}+5 \%$ horse blood. Following stimulation, LDCL was measured every 2 min over a total period of 60 $\min$ at $37^{\circ} \mathrm{C}$ using a SpectraMax M5 plate reader (Molecular Devices).

\section{Results}

\section{Generation and characterisation of $\boldsymbol{N}$. meningitidis porin mutants}

Mutations in each porin gene of $N$. meningitidis were made by allelic replacement via homologous recombination during natural DNA transformation with an inactivated allele carrying an antibiotic resistance marker. Plasmids pPorA::Tet and pPorB:Cat (Fig 1) were linearized and transformed into MC58 to generate strains $58 \Delta \mathrm{A}$ and $58 \Delta \mathrm{B}$ respectively. The linearized pGEMporB::Cat was subsequently transformed into $58 \Delta \mathrm{A}$ to generate $58 \Delta \mathrm{AB}$. Acapsulate strains lacking expression of either PorA or PorB had been previously generated $^{12}$ designated $\phi 9 D$ PorA and $\phi 9 D$ PorB. Strain $\phi 9 D$ PorAB was generated by transformation of $\phi 9 \mathrm{DP}$ orA with pPorB:Cat, demonstrating that capsular polysaccharide is not required to generate meningococci lacking both major porins, strain $\phi 9 \mathrm{DP}$ PrAB.

Sequencing of PCR products from por $B$ regions of the transformants confirmed replacement of the wild-type por $B$ allele with the por $B:: c a t$ allele, and full genome and sequence analysis confirmed no disruption or alteration in upstream or downstream genes, nor evidence of other chromosomal rearrangements or duplications: the double porin mutant strain $58 \Delta \mathrm{AB}$ contained no unique SNPs or INDELs (data not shown). SDS-PAGE analysis confirmed that expression of PorA, PorB, or both had been abolished in the respective strains (Fig 2). Western immunoblot (Fig 2) and MS analysis of major bands confirmed the identity of the major bands (Supplementary Figure 1). 


\section{SWATH-MS proteomic analysis}

We were able to generate $N$. meningitidis cells with abolition of expression of both major porins, and with no detectable genomic changes associated with deletion of PorA and PorB. In order to determine if any compensatory protein expression changes were apparent in the double porin mutant, and to gain insights into the normal role of PorA and PorB, we performed relative quantification of the global cellular proteomes of MC58, 58 $\Delta \mathrm{A}, 58 \Delta \mathrm{B}$ and $58 \triangle \mathrm{AB}$ using SWATH-MS. Whole cell proteomics of these strains identified a total of 413 unique proteins (Supplementary Table S1), 400 of which were used in SWATH-MS analysis. SWATH-MS data was analysed considering proteins which showed significant $(\mathrm{P}<0.05)$ and large (greater than $30 \%)$ changes in expression. Relative quantification of cellular proteomes using SWATH-MS identified 9 proteins (2.3\%) with higher abundance, and 2 proteins $(0.5 \%)$ with lower abundance in $58 \Delta \mathrm{A}$ than MC58 (Supplementary Table S2, Fig $3 \mathrm{~A}$ ). In contrast, the $58 \Delta \mathrm{B}$ strain showed substantially more changes in global proteome relative to MC58, with 12 proteins (3\%) with higher abundance, and 14 proteins (3.5\%) with lower abundance (Supplementary Table S3, Fig 3B). Deletion of both porA and porB (strain $58 \triangle \mathrm{AB}$ ) showed many large changes in expression relative to the parental MC58, with 33 proteins $(8.3 \%)$ with higher abundance and $34(8.5 \%)$ with lower abundance (Supplementary Table S4, Fig 3C). Consistent with this, 2 proteins ( $0.5 \%)$ had higher abundance and 9 proteins $(2.2 \%$ ) had lower abundance in $58 \Delta \mathrm{B}$ compared with $58 \Delta \mathrm{A}$ (Supplementary Table S5, Fig 3D). Untargeted SWATH-MS relative quantification of global cellular proteomes confirmed the absence of PorA and PorB expression where expected, as these proteins showed the largest fold change reductions in expression in the respective mutant strains (Supplementary Tables S2, S3 and S4, Fig 3F,G). Residual apparent detection of PorA or PorB protein in respective deletion strains was due to measurement of background inherent in SWATH-MS measurements. Expression of PorA and PorB were upregulated in the reciprocal mutants, suggesting partial functional complementation (Fig 3F, G). This was not an artefact due to the abundance of PorA and PorB, as these proteins contribute only $\sim 5 \%$ of total MS ion intensity to the global peptide intensity count. Examination of RNA levels indicated that the por $A$ transcript was 5.5 fold more abundant in strain $58 \Delta \mathrm{B}$ than in the parental MC58 strain (relative to 16S RNA), whereas porB transcript was similar in MC58 and $58 \Delta \mathrm{A}$.

Amongst other proteins that were significantly more abundant $\left(\mathrm{P}<10^{-10}\right)$ in strains lacking PorB $(58 \Delta \mathrm{B}$ and $58 \Delta \mathrm{AB})$ relative to MC58 and 58 $\mathrm{A}$ strains, NMB1963 encodes a putative $\mathrm{ABC}$ transporter with similarity to a toluene tolerance family, and NMB1963 and its associated operon has been implicated in glutamate uptake in low sodium ion environments ${ }^{32}$. RmpM, a protein that forms complexes with porins, and stabilises Neisseria outer membrane proteins ${ }^{33-34}$, also was over-represented in $58 \Delta \mathrm{B}$ and $58 \Delta \mathrm{AB}$ relative to MC58 and 58 $\Delta \mathrm{A}$ strains. Opc, a trimeric beta-barrel protein ${ }^{35}$, was identified as being more abundant in the double porin knockout compared with all other strains. NMB0995, (macrophage infectivity potentiator-related protein) was also increased in strain $58 \Delta \mathrm{AB}$ compared with all other strains, as was NMB1030 (Fig 3K), recently characterised as a ubiquinone binding protein ${ }^{36}$. 


\section{Determination of growth requirement of porin mutants}

Growth in Levinthal's-supplemented BHI broth was assessed. Abolition of both porins did not reduce growth rate to a large extent in this rich medium (which contains heated, clarified horse serum), with the growth rate in the exponential phase not significantly different between any of the strains when calculated by comparing slope of the curve (Fig 4). Calculation of generation times revealed small but significantly increased generation times for $58 \Delta \mathrm{B}$ and $58 \Delta \mathrm{AB}$ compared to MC58 and $58 \Delta \mathrm{A}$ (supplementary table S6). At each time point the $58 \triangle \mathrm{AB}$ strain exhibited lower OD than MC58 ( $\mathrm{P}<0.05$, independent $\mathrm{t}-\mathrm{Test})$, and reached lower OD at stationary phase (Fig 4 ). Bacterial numbers were similar in samples taken from these cultures at $\mathrm{A} 600=1$.

To further characterise growth, bacterial colony growth was observed on solid media. Growth was poor on GCB plates containing Kellogg's supplements or IsoVitalex (Fig 5), which are both supplements that are routinely used for growth of Neisseria. As NMB1030, $\mathrm{NMB} 0995$, and Opc are all upregulated during growth in human blood ${ }^{37}$, and these proteins were each upregulated in the $58 \triangle \mathrm{AB}$ strain (Fig 4), we assessed growth with blood and blood derivatives. Qualitative observations indicated that strain $58 \triangle \mathrm{AB}$ grew reasonably well on medium containing 5\% equine blood or serum (Fig 5). Treatment of serum with chelex or nucleases to remove divalent cations and DNA/RNA, respectively did not reduce growth. Growth was similar on GCB when supplemented with porcine or bovine blood, and on media supplemented with human hemoglobin, porcine or fetal bovine serum (not shown), whereas colony size was not enhanced with bovine hemin (Fig 5). These observations suggest a nutrition acquisition defect for the $58 \triangle \mathrm{AB}$ strain that is complemented by growth with blood or blood derivative.

\section{Effect on host cells: modification of oxidative burst}

Porin purified from $N$. gonorrhoeae has previously been demonstrated to directly affect the oxidative burst of human neutrophils ${ }^{38}$, and gonococcal infection of HL-60 cells inhibits PMA-induced oxidative burst ${ }^{39}$. We tested the ability of meningococci lacking both PorA and PorB to inhibit luminol-dependent chemiluminescence induced by PMA in differentiated HL-60 cells, using $N$. gonorrhoeae as a positive control (Fig 6A). The porin mutant strain lacking both PorA and PorB did not differ in its ability to inhibit PMA-induced ROS production relative to wild-type $N$. gonorrhoeae or $N$. meningitidis. Meningococcal mutants lacking either PorA or PorB singly also inhibited PMA-induced ROS production to the same extent as the wild-type strain, and none of the strains tested induced ROS production from HL-60 cells in the absence of PMA (data not shown).

\section{Effect on host cells: inhibition of apoptosis}

PorB has been cited as having a role in either inducing ${ }^{13-14}$ or protecting against apoptosis $^{15-18,39}$. We tested the effect of PorA and/or PorB mutation on the modulation of cellular apoptosis during infection. HL-60 cells were differentiated towards granulocyte phenotype for 5 days using $0.7 \%$ dimethylformamide as previously described ${ }^{39}$ and the capacity of meningococci to inhibit staurosporine-induced apoptosis was assessed in granulocyte-differentiated HL-60 cells (Fig 6B). As expected ${ }^{39}$, N. gonorrhoeae inhibited apoptosis induced by STS, indicated by decreased caspase- 3 activity relative to STS-treated, 
uninfected cells, as did the porin-replete meningococcal strain. The acapsulate meningococcal $\phi 9 \mathrm{DAB}$ strain lacking both PorA and PorB was equally effective at inhibiting staurosporine-induced caspase- 3 activity relative to both of the wild-type strains.

\section{Discussion}

This study is the first report of the generation of a $N$. meningitidis strain that lacks both major porins. This was unexpected as it is not possible to generate a mutant of the closely related $N$. gonorrhoeae that lacks its single, major porin, PIB. A major difference between the two species is the presence of a capsular polysaccharide in $N$. meningitidis. However, capsule is not required for survival of $N$. meningitidis in the absence of major porins, as we were able to generate an acapsulate strain lacking both PorA and PorB expression (Supplementary Fig 1). Western immunoblot of capsulate strains indicated the absence of the porins (Fig 2), and MS analysis of total cellular protein confirmed that the major porins were absent (Fig 3). In the single porin mutant strains, the relative proportion of the reciprocal porin was higher, suggesting compensatory upregulation (Fig 3F, G). The increased transcript level of por $A$ in the $58 \Delta \mathrm{B}$ strain indicates transcriptional compensation. Conversely, in the $58 \Delta \mathrm{A}$ strain, the slight increase in PorB protein level detected by SWATH-MS was not matched by an increased porB transcript level, suggesting that PorB protein content is influenced on a post-transcriptional mechanism.

We analysed the proteome of the strains to determine whether compensatory changes occur in the absence of porins. Lack of PorA resulted in few changes whereas deletion of PorB resulted in an increased set of differentially expressed proteins. Loss of both major porins resulted in even further changes. These results are consistent with the observation that PorA is more dispensable than PorB: naturally occurring PorB-lacking strains have not been reported, and PorB has an important in vivo function, whereas clinical isolates lacking PorA are described, and PorA is naturally phase-variable.

The Neisseria protein RmpM protein was over-represented in total cellular protein, as assessed by quantitative- SWATH-MS analysis, in strains lacking either PorB alone, or both PorB and PorA. This suggests that in the absence of the major porin PorB, RmpM is upregulated and may be required to stabilise other protein complexes, or may be required for membrane stabilisation. However, it is of note that RmpM is not apparent as a major band in sarkosyl-extracted outer-membrane proteins of a strain lacking both major porins (Supplementary figure 1). RmpM forms complexes with porins and other outer membrane proteins $^{3,33,40}$, and is associated with Omp85/ $\beta$-barrel assembly machinery ${ }^{34}$, and the absence of PorA and PorB may thus reduce the association of this protein with membrane proteins in this detergent. PorA, PorB, and RmpM are reported to be upregulated after prolonged growth with human epithelial cells ${ }^{41}$, indicating an important role for these proteins in interactions with host cells. In strain $58 \Delta \mathrm{AB}$, Opc is more abundant. The Opc protein is phase-variably expressed through alterations in length of a poly $(\mathrm{C})$ tract in its promoter $^{42}$. Genome sequence analysis revealed no alterations in the promoter region of the opc gene in the $58 \triangle \mathrm{AB}$ strain, suggesting that the increased abundance of this protein (Fig $4 \mathrm{H}$ ) is the result of regulatory changes rather than the result of phase-variation. Indeed, opc is reported as induced during growth in serum ${ }^{37}$. 
NMB1963 is part of a glutamate uptake operon ${ }^{32}$. The protein encoded by this gene was more abundant in strains $58 \Delta \mathrm{B}$ and $58 \Delta \mathrm{AB}$, both of which lack PorB. $N$. meningitidis does not contain a glutamine synthase gene, and must therefore rely on glutamate uptake. The upregulation of NMB1963 may be an indication of compensatory upregulation to rescue general nutrient stress when major porins are absent, or may suggest that PorB has an unrecognised role in amino acid uptake. Other proteins with altered abundance indicative of changes in nutrient and/or energy metabolism included SucA (NMB0995) and SucC (NMB0959), downregulated in the PorAB mutant strain, as well as reductions of PpsA (phosphoenolpyruvate synthase, NMB0618), AdhP (alcohol dehydrogenase, propanolpreferring, NMB0546), and AcnB (aconitate hydratase, NMB1572.) Cellular processes associated with proline also appear to be affected, with downregulation of ProS (NMB0133) and PutA (NMB0401) in the double mutant, strain 58 $\triangle \mathrm{AB}$.

As an alternate role for the upregulation of NMB1963, glutamate has several cellular fates after uptake, including synthesis of glutathione, an important molecule in maintenance of intracellular redox state. A mutant of the glutamate GltT ABC type transporter (NMB1965, in the same operon as NMB1963) has recently been reported to have significantly reduced glutathione content. This strain was attenuated in vivo, and GltT was shown to have a significant role in bacterial resistance to neutrophil oxidative burst ${ }^{43}$. Mutants of GltT were significantly more susceptible to $\mathrm{H}_{2} \mathrm{O}_{2}{ }^{43}$. The protein encoded by NMB0995 was also overrepresented in the total protein sample of strain $58 \triangle \mathrm{AB}$ compared with all other strains. This protein belongs to the family of macrophage infectivity potentiator-related proteins. The exact function of these proteins are unclear, but MIP-related proteins contain conserved domains of the TIGR01926 family, some of which are known to act as peroxidases, or correlate with resistance to oxidative stress. Other proteins were upregulated in the double porins mutant strain that are indicative of an alteration of intracellular redox state:

NMB1044 (fpr1), NMB0946 (encoding peroxiredoxin 2 family protein). The increased abundance of these proteins indicate that cells may be under additional oxidative stress as a result of PorAB abrogation, but this link remains to be experimentally assessed. DnaK (molecular chaperone, NMB0554) and DsbA2 were also upregulated, suggesting protein synthesis and stabilisation is affected.

In light of these obvious changes in protein expression (which were not attributable to selection of compensatory mutations in the double porin mutant), it was noted that growth on solid media was improved when blood products were added, specifically blood, serum, or human hemoglobin. Growth in a rich liquid medium containing Levinthal's supplement (which includes horse blood) is slightly reduced in the absence of PorB, and stationary phase was reached at a lower OD for $58 \triangle \mathrm{AB}$. PorB mutants have previously been described as having "slightly reduced" growth rates 2 .

We next investigated the effect of porin deletion on interactions between $N$. meningitidis and granulocytes. Considerable evidence exists to suggest that porins of Neisseria, in particular PorB, can function to modulate apoptotic signaling in various eukaryotic cell types ${ }^{13-16,44-46}$. Porin has also been shown to affect the oxidative burst in phagocytic cells $^{38-39,47-48}$, and for these reasons we investigated the ability of the $N$. meningitidis double mutants to inhibit both apoptosis and the oxidative burst in granulocytic HL-60 cells. 
Our results suggest that meningococci lacking both PorA and PorB are still able to inhibit both STS-induced apoptosis and a PMA-induced oxidative burst to the same extent as the parental strain, contrary to our expectations. Potential explanations for our lack of observed phenotype are either (i) an alternate neisserial outer membrane protein is complementing the function of PorB (and/or PorA) with respect its effects on eukaryotic cell survival and function, or (ii) PorA or PorB do not play a significant role for either apoptosis inhibition or regulation of ROS production. Future analysis will be required to test between these hypotheses.

In summary, we report that $N$. meningitidis lacking the major porins are viable. This differs from the related $N$. gonorrhoeae which is not viable without PorB. Proteomic analysis indicates that deletion of both major porins results in compensatory alterations in metabolism, specifically likely affecting intracellular redox state. Future studies will focus on further characterising the functional importance of porins in the biology of the pathogenic Neisseria, and their interaction with host cells.

\section{Supplementary Material}

Refer to Web version on PubMed Central for supplementary material.

\section{Acknowledgments}

MPJ received funding from NHMRC program grant 565526, NHMRC program grant 1071659, and ARC Discovery Project grant 13010314. HSS received funding from NIH grants R01 AI044239 and R37 AI033493 to HSS

\section{References}

1. Massari P, Ram S, Macleod H, Wetzler LM. The role of porins in neisserial pathogenesis and immunity. Trends in microbiology. 2003; 11(2):87-93. [PubMed: 12598131]

2. Tommassen J, Vermeij P, Struyve M, Benz R, Poolman JT. Isolation of Neisseria meningitidis mutants deficient in class 1 (porA) and class 3 (porB) outer membrane proteins. Infection and immunity. 1990; 58(5):1355-9. [PubMed: 2157669]

3. Jansen C, Wiese A, Reubsaet L, Dekker N, de Cock H, Seydel U, Tommassen J. Biochemical and biophysical characterization of in vitro folded outer membrane porin PorA of Neisseria meningitidis. Biochimica et biophysica acta. 2000; 1464(2):284-98. [PubMed: 10727615]

4. Tanabe M, Nimigean CM, Iverson TM. Structural basis for solute transport, nucleotide regulation and immunological recognition of Neisseria meningitidis PorB. Proceedings of the National Academy of Sciences of the United States of America. 2010; 107(15):6811-6. [PubMed: 20351243]

5. Song J, Minetti CA, Blake MS, Colombini M. Successful recovery of the normal electrophysiological properties of PorB (class 3) porin from Neisseria meningitidis after expression in Escherichia coli and renaturation. Biochimica et biophysica acta. 1998; 1370(2):289-98. [PubMed: 9545584]

6. Whiley DM, Limnios A, Moon NJ, Gehrig N, Goire N, Hogan T, Lam A, Jacob K, Lambert SB, Nissen MD, Sloots TP. False-negative results using Neisseria gonorrhoeae porA pseudogene PCR a clinical gonococcal isolate with an N. meningitidis porA sequence, Australia, March 2011. Euro surveillance: bulletin Europeen sur les maladies transmissibles = European communicable disease bulletin. 2011; 16(21)

7. van der Ende A, Hopman CT, Zaat S, Essink BB, Berkhout B, Dankert J. Variable expression of class 1 outer membrane protein in Neisseria meningitidis is caused by variation in the spacing between the -10 and -35 regions of the promoter. Journal of bacteriology. 1995; 177(9):2475-80. [PubMed: 7730280] 
8. van der Ende A, Hopman CT, Keijzers WC, Spanjaard L, Lodder EB, van Keulen PH, Dankert J. Outbreak of meningococcal disease caused by PorA-deficient meningococci. The Journal of infectious diseases. 2003; 187(5):869-71. [PubMed: 12599063]

9. Crowe BA, Wall RA, Kusecek B, Neumann B, Olyhoek T, Abdillahi H, Hassan-King M, Greenwood BM, Poolman JT, Achtman M. Clonal and variable properties of Neisseria meningitidis isolated from cases and carriers during and after an epidemic in The Gambia, West Africa. The Journal of infectious diseases. 1989; 159(4):686-700. [PubMed: 2494268]

10. Bauer FJ, Rudel T, Stein M, Meyer TF. Mutagenesis of the Neisseria gonorrhoeae porin reduces invasion in epithelial cells and enhances phagocyte responsiveness. Molecular microbiology. 1999; 31(3):903-13. [PubMed: 10048033]

11. Rudel T, Schmid A, Benz R, Kolb HA, Lang F, Meyer TF. Modulation of Neisseria porin (PorB) by cytosolic ATP/GTP of target cells: parallels between pathogen accommodation and mitochondrial endosymbiosis. Cell. 1996; 85(3):391-402. [PubMed: 8616894]

12. Peak IR, Jennings CD, Jen FE, Jennings MP. Role of Neisseria meningitidis PorA and PorB expression in antimicrobial susceptibility. Antimicrobial agents and chemotherapy. 2014; 58(1): 614-6. [PubMed: 24145542]

13. Muller A, Gunther D, Dux F, Naumann M, Meyer TF, Rudel T. Neisserial porin (PorB) causes rapid calcium influx in target cells and induces apoptosis by the activation of cysteine proteases. The EMBO journal. 1999; 18(2):339-52. [PubMed: 9889191]

14. Muller A, Gunther D, Brinkmann V, Hurwitz R, Meyer TF, Rudel T. Targeting of the pro-apoptotic VDAC-like porin (PorB) of Neisseria gonorrhoeae to mitochondria of infected cells. The EMBO journal. 2000; 19(20):5332-43. [PubMed: 11032801]

15. Massari P, Ho Y, Wetzler LM. Neisseria meningitidis porin PorB interacts with mitochondria and protects cells from apoptosis. Proceedings of the National Academy of Sciences of the United States of America. 2000; 97(16):9070-5. [PubMed: 10922061]

16. Massari P, King CA, Ho AY, Wetzler LM. Neisserial PorB is translocated to the mitochondria of HeLa cells infected with Neisseria meningitidis and protects cells from apoptosis. Cellular microbiology. 2003; 5(2):99-109. [PubMed: 12580946]

17. Tunbridge AJ, Stevanin TM, Lee M, Marriott HM, Moir JW, Read RC, Dockrell DH. Inhibition of macrophage apoptosis by Neisseria meningitidis requires nitric oxide detoxification mechanisms. Infection and immunity. 2006; 74(1):729-33. [PubMed: 16369030]

18. Chen A, Seifert HS. Saturating mutagenesis of an essential gene: a majority of the Neisseria gonorrhoeae major outer membrane porin (PorB) is mutable. Journal of bacteriology. 2014; 196(3):540-7. [PubMed: 24244002]

19. Chen A, Seifert HS. Structure-function studies of the Neisseria gonorrhoeae major outer membrane porin. Infection and immunity. 2013; 81(12):4383-91. [PubMed: 24042111]

20. Kellogg DS Jr, Peacock WL Jr, Deacon WE, Brown L, Pirkle DI. Neisseria gonorrhoeae. I. Virulence Genetically Linked to Clonal Variation. Journal of bacteriology. 1963; 85:1274-9. [PubMed: 14047217]

21. Warren MJ, Roddam LF, Power PM, Terry TD, Jennings MP. Analysis of the role of pgII in pilin glycosylation of Neisseria meningitidis. FEMS immunology and medical microbiology. 2004; 41(1):43-50. [PubMed: 15094166]

22. Srikhanta YN, Dowideit SJ, Edwards JL, Falsetta ML, Wu HJ, Harrison OB, Fox KL, Seib KL, Maguire TL, Wang AH, Maiden MC, Grimmond SM, Apicella MA, Jennings MP. Phasevarions mediate random switching of gene expression in pathogenic Neisseria. PLoS pathogens. 2009; 5(4):e1000400. [PubMed: 19390608]

23. Blakeway LV, Power PM, Jen FE, Worboys SR, Boitano M, Clark TA, Korlach J, Bakaletz LO, Jennings MP, Peak IR, Seib KL. ModM DNA methyltransferase methylome analysis reveals a potential role for Moraxella catarrhalis phasevarions in otitis media. FASEB journal: official publication of the Federation of American Societies for Experimental Biology. 2014

24. Bailey UM, Jamaluddin MF, Schulz BL. Analysis of congenital disorder of glycosylation-Id in a yeast model system shows diverse site-specific under-glycosylation of glycoproteins. Journal of proteome research. 2012; 11(11):5376-83. [PubMed: 23038983] 
25. Gillet LC, Navarro P, Tate S, Rost H, Selevsek N, Reiter L, Bonner R, Aebersold R. Targeted data extraction of the MS/MS spectra generated by data-independent acquisition: a new concept for consistent and accurate proteome analysis. Molecular \& cellular proteomics: MCP. 2012; 11(6):O111016717.

26. Xu Y, Bailey UM, Schulz BL. Automated measurement of site-specific N-glycosylation occupancy with SWATH-MS. Proteomics. 2015

27. Bailey UM, Punyadeera C, Cooper-White JJ, Schulz BL. Analysis of the extreme diversity of salivary alpha-amylase isoforms generated by physiological proteolysis using liquid chromatography-tandem mass spectrometry. Journal of chromatography. B, Analytical technologies in the biomedical and life sciences. 2012; 911:21-6. [PubMed: 23217301]

28. Choi M, Chang CY, Clough T, Broudy D, Killeen T, MacLean B, Vitek O. MSstats: an R package for statistical analysis of quantitative mass spectrometry-based proteomic experiments. Bioinformatics. 2014; 30(17):2524-6. [PubMed: 24794931]

29. Bankevich A, Nurk S, Antipov D, Gurevich AA, Dvorkin M, Kulikov AS, Lesin VM, Nikolenko SI, Pham S, Prjibelski AD, Pyshkin AV, Sirotkin AV, Vyahhi N, Tesler G, Alekseyev MA, Pevzner PA. SPAdes: a new genome assembly algorithm and its applications to single-cell sequencing. Journal of computational biology: a journal of computational molecular cell biology. 2012; 19(5): 455-77. [PubMed: 22506599]

30. Nikolenko SI, Korobeynikov AI, Alekseyev MA. BayesHammer: Bayesian clustering for error correction in single-cell sequencing. BMC genomics. 2013; 14(Suppl 1):S7.

31. Koboldt DC, Zhang Q, Larson DE, Shen D, McLellan MD, Lin L, Miller CA, Mardis ER, Ding L, Wilson RK. VarScan 2: somatic mutation and copy number alteration discovery in cancer by exome sequencing. Genome research. 2012; 22(3):568-76. [PubMed: 22300766]

32. Monaco C, Tala A, Spinosa MR, Progida C, De Nitto E, Gaballo A, Bruni CB, Bucci C, Alifano P. Identification of a meningococcal L-glutamate $\mathrm{ABC}$ transporter operon essential for growth in low-sodium environments. Infection and immunity. 2006; 74(3):1725-40. [PubMed: 16495545]

33. Marzoa J, Abel A, Sanchez S, Chan H, Feavers I, Criado MT, Ferreiros CM. Analysis of outer membrane porin complexes of Neisseria meningitidis in wild-type and specific knock-out mutant strains. Proteomics. 2009; 9(3):648-56. [PubMed: 19137557]

34. Volokhina EB, Beckers F, Tommassen J, Bos MP. The beta-barrel outer membrane protein assembly complex of Neisseria meningitidis. Journal of bacteriology. 2009; 191(22):7074-85. [PubMed: 19767435]

35. Collins R, Achtman M, Ford R, Bullough P, Derrick J. Projection structure of reconstituted Opc outer membrane protein from Neisseria meningitidis. Molecular microbiology. 1999; 32(1):217-9. [PubMed: 10216874]

36. Donnarumma D, Golfieri G, Brier S, Castagnini M, Veggi D, Bottomley MJ, Delany I, Norais N. Neisseria meningitis GNA1030 is a ubiquinone-8 binding protein. FASEB journal: official publication of the Federation of American Societies for Experimental Biology. 2015

37. Echenique-Rivera H, Muzzi A, Del Tordello E, Seib KL, Francois P, Rappuoli R, Pizza M, Serruto D. Transcriptome analysis of Neisseria meningitidis in human whole blood and mutagenesis studies identify virulence factors involved in blood survival. PLoS pathogens. 2011; 7(5):e1002027. [PubMed: 21589640]

38. Lorenzen DR, Gunther D, Pandit J, Rudel T, Brandt E, Meyer TF. Neisseria gonorrhoeae porin modifies the oxidative burst of human professional phagocytes. Infection and immunity. 2000; 68(11):6215-22. [PubMed: 11035728]

39. Chen A, Seifert HS. Neisseria gonorrhoeae-mediated inhibition of apoptotic signalling in polymorphonuclear leukocytes. Infection and immunity. 2011; 79(11):4447-58. [PubMed: 21844239]

40. Prinz T, Tommassen J. Association of iron-regulated outer membrane proteins of Neisseria meningitidis with the RmpM (class 4) protein. FEMS microbiology letters. 2000; 183(1):49-53. [PubMed: 10650201]

41. Hey A, Li MS, Hudson MJ, Langford PR, Kroll JS. Transcriptional profiling of Neisseria meningitidis interacting with human epithelial cells in a long-term in vitro colonization model. Infection and immunity. 2013; 81(11):4149-59. [PubMed: 23980104] 
42. Sarkari J, Pandit N, Moxon ER, Achtman M. Variable expression of the Opc outer membrane protein in Neisseria meningitidis is caused by size variation of a promoter containing polycytidine. Molecular microbiology. 1994; 13(2):207-17. [PubMed: 7984102]

43. Tala A, Monaco C, Nagorska K, Exley RM, Corbett A, Zychlinsky A, Alifano P, Tang CM. Glutamate utilization promotes meningococcal survival in vivo through avoidance of the neutrophil oxidative burst. Molecular microbiology. 2011; 81(5):1330-42. [PubMed: 21777301]

44. Muller A, Rassow J, Grimm J, Machuy N, Meyer TF, Rudel T. VDAC and the bacterial porin PorB of Neisseria gonorrhoeae share mitochondrial import pathways. The EMBO journal. 2002; 21(8): 1916-29. [PubMed: 11953311]

45. Binnicker MJ, Williams RD, Apicella MA. Gonococcal porin IB activates NF-kappaB in human urethral epithelium and increases the expression of host antiapoptotic factors. Infection and immunity. 2004; 72(11):6408-17. [PubMed: 15501771]

46. Kozjak-Pavlovic V, Dian-Lothrop EA, Meinecke M, Kepp O, Ross K, Rajalingam K, Harsman A, Hauf E, Brinkmann V, Gunther D, Herrmann I, Hurwitz R, Rassow J, Wagner R, Rudel T. Bacterial porin disrupts mitochondrial membrane potential and sensitizes host cells to apoptosis. PLoS pathogens. 2009; 5(10):e1000629. [PubMed: 19851451]

47. Bjerknes R, Guttormsen HK, Solberg CO, Wetzler LM. Neisserial porins inhibit human neutrophil actin polymerization, degranulation, opsonin receptor expression, and phagocytosis but prime the neutrophils to increase their oxidative burst. Infection and immunity. 1995; 63(1):160-7. [PubMed: 7806353]

48. Criss AK, Seifert HS. Neisseria gonorrhoeae suppresses the oxidative burst of human polymorphonuclear leukocytes. Cellular microbiology. 2008; 10(11):2257-70. [PubMed: 18684112] 

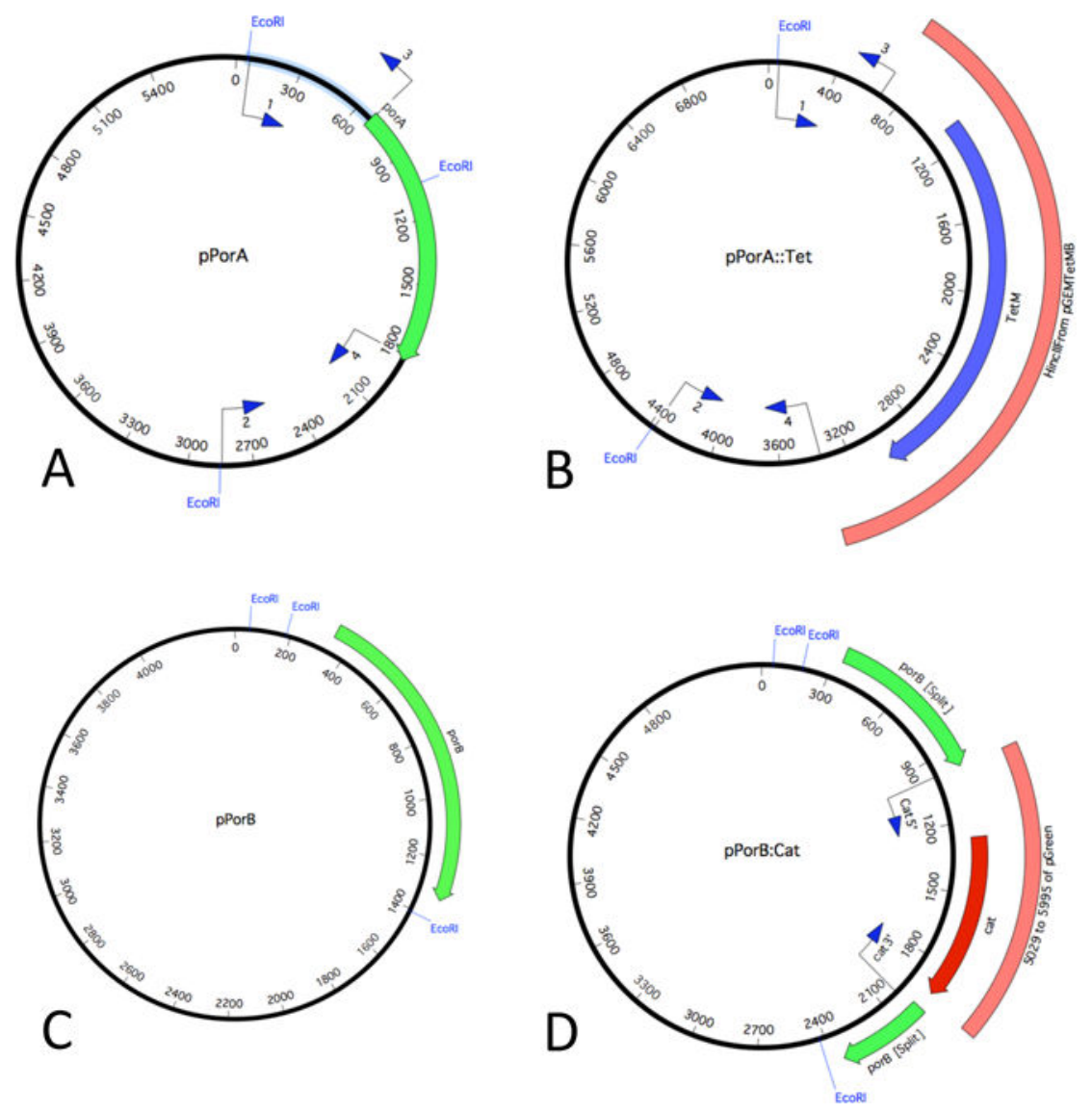

Figure 1. Plasmids generated for deletion of porin genes

The por $A$ and por $B$ genes were amplified and cloned into pGEMTeasy (A,C). B: After deletion of por $A$ by PCR, an HincII fragment (orange box) from pGem-TetMB containing tetracycline resistance (blue gene) ${ }^{21}$ was cloned into pPorA to generate pPorA::Tet. D: A fragment was amplified from pCmGFP (pGreen, orange box) containing the chloramphenicol acetyl transferase gene (red gene) and introduced into a PCR engineered site in $\operatorname{por} B$, to generatepPorB:Cat. 


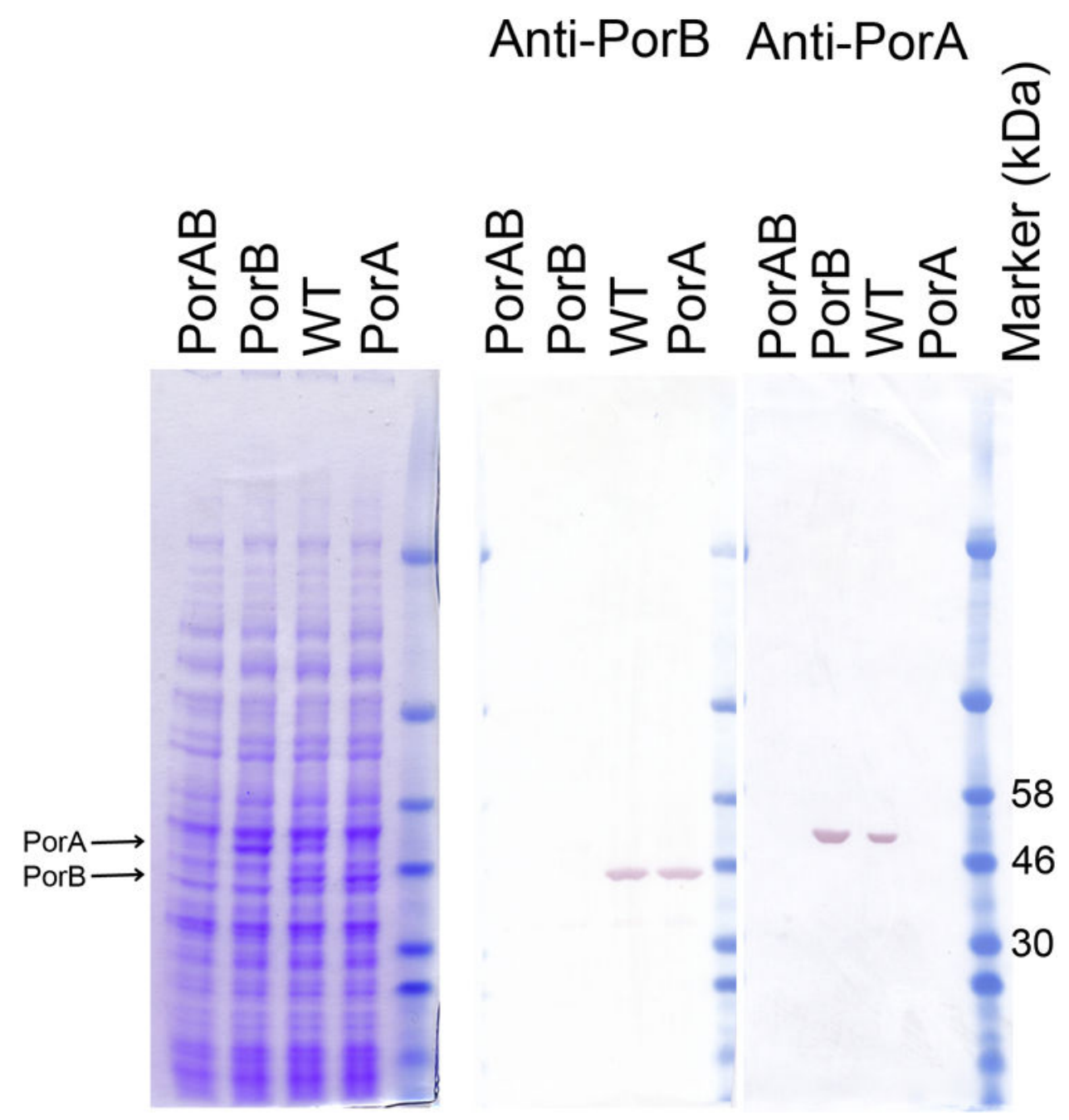

Figure 2. Confirmation of abolition of Porin expression Bacteria were harvested from liquid cultures (OD A600=1) and separated electrophoretically. Gels containing total cellular protein from strains MC58, 58 $\triangle$ PorA, $58 \Delta$ PorB and 58 $\Delta$ PorAB (labelled WT, PorA, PorB, or PorAB respectively) were commassie stained, or western blotted and probed with antibodies specific for PorA or PorB. 

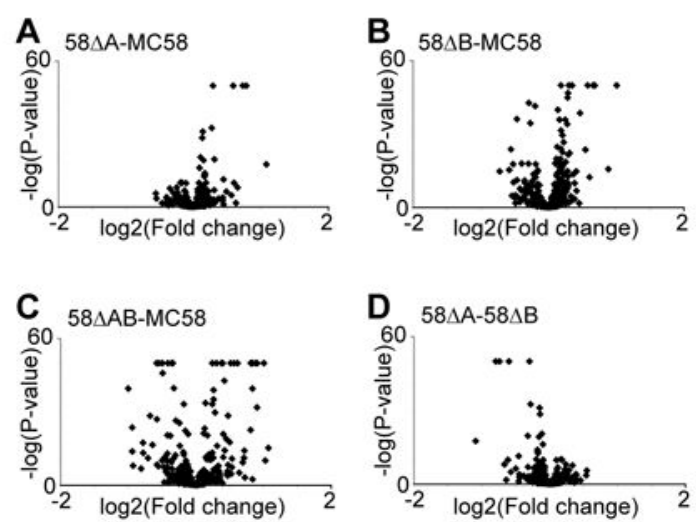

\section{E}
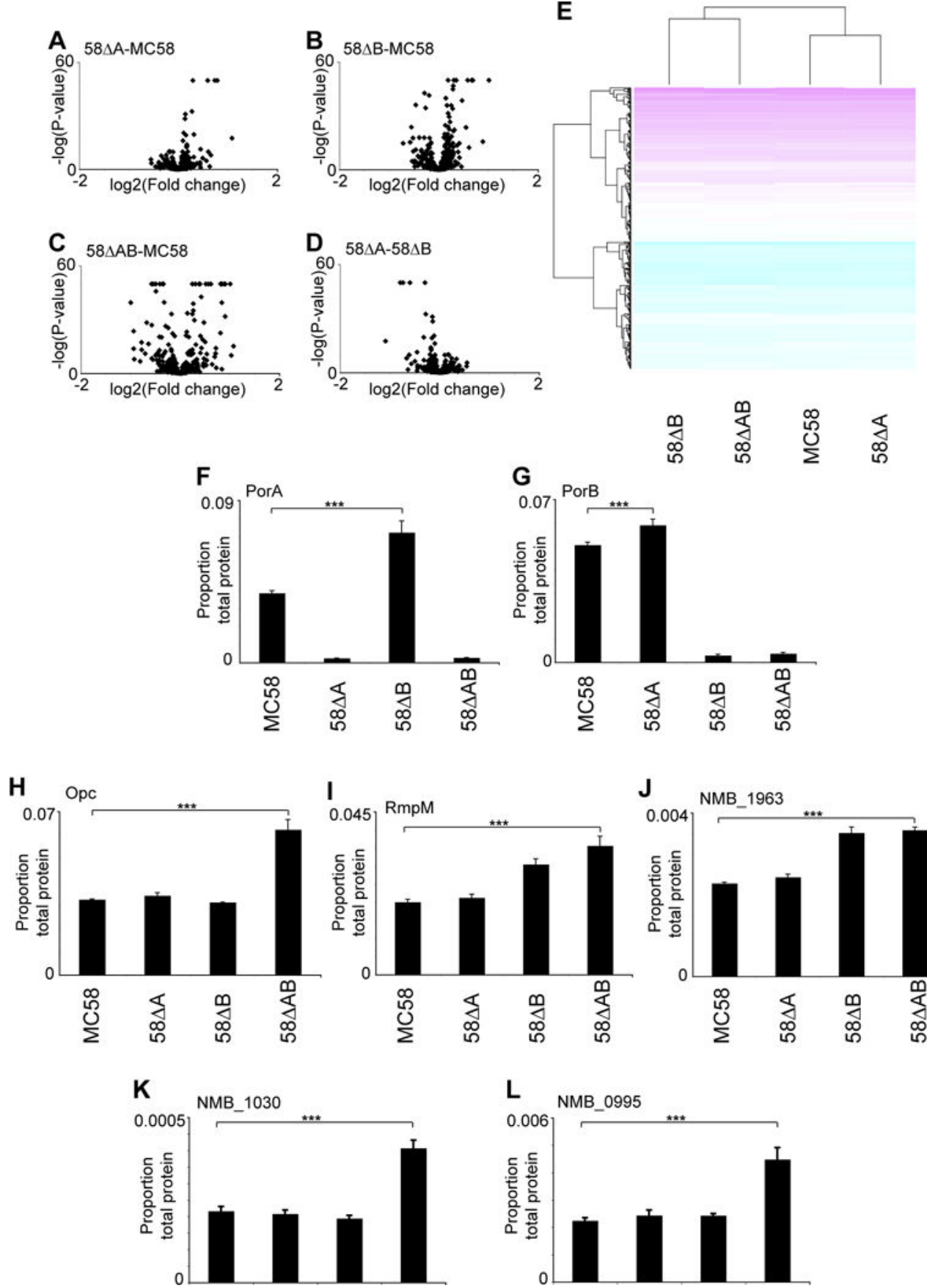

Figure 3.

SWATH-MS relative quantification of PorA and PorB-dependent changes in global meningococcal proteome. Volcano plots for (A) $58 \Delta \mathrm{A}$ versus MC58, (B) $58 \Delta \mathrm{B}$ versus MC58, (C) $58 \Delta \mathrm{AB}$ versus MC58, (D) $58 \Delta \mathrm{A}$ versus $58 \Delta \mathrm{B}$. (E) Clustered heat map of protein expression in MC58, 58 $\Delta \mathrm{A}, 58 \Delta \mathrm{B}$ and $58 \Delta \mathrm{AB}$. Protein abundance in MC58, 58 $\Delta \mathrm{A}, 58 \Delta \mathrm{B}$ and 58 $\triangle \mathrm{AB}$ for (F) PorA, (G) PorB, (H) Opc, (I) RmpM, (J) NMB1963, (K) NMB1030, and (L) NMB0995. For F-L, ***, $\mathrm{P}<0.001$ 


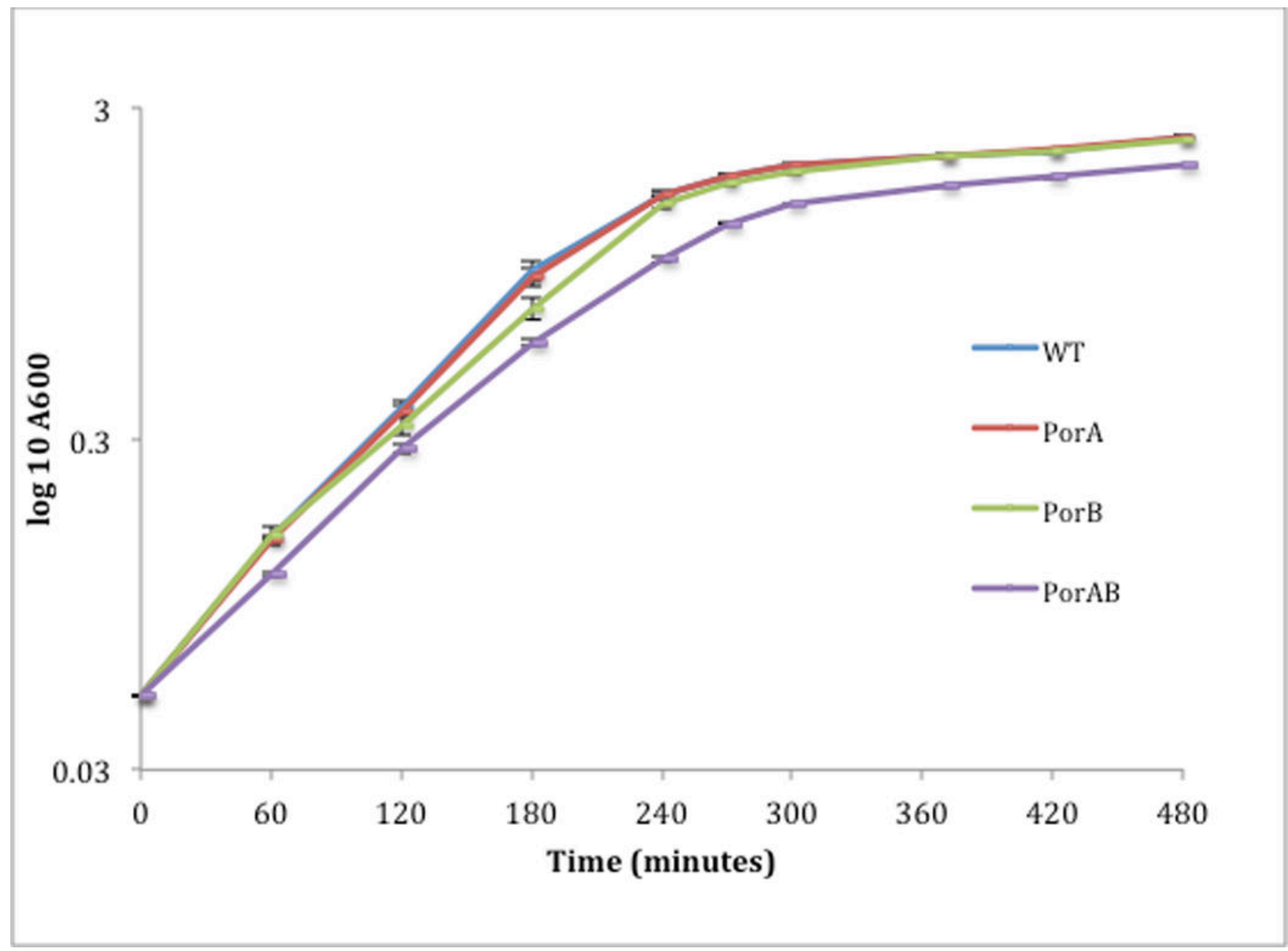

Figure 4.

Growth curve of parental and porin deficient strains in rich media. Each data point represents the mean of three replicate cultures, \pm SD. 


\section{MC58 wt colonies}

Horse blood [ $5 \%$ ]

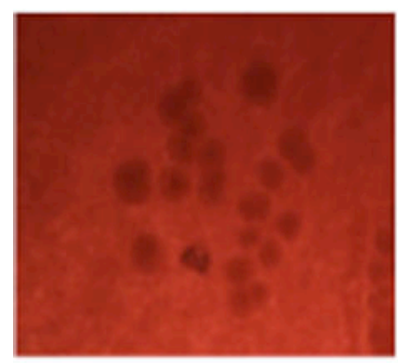

Horse serum + chelex

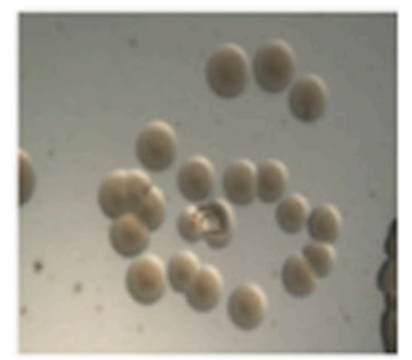

IsoVitaleX

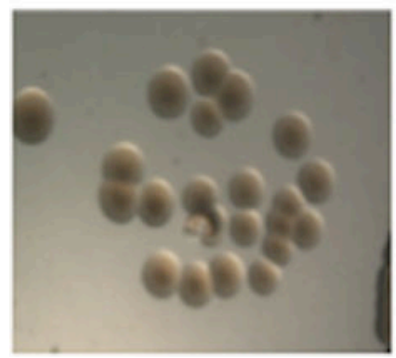

Horse serum (5\%)

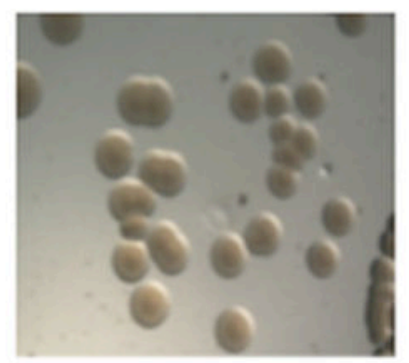

Bovine hemin

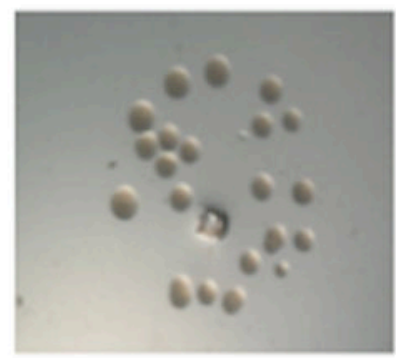

GCB + Kellogg's supps

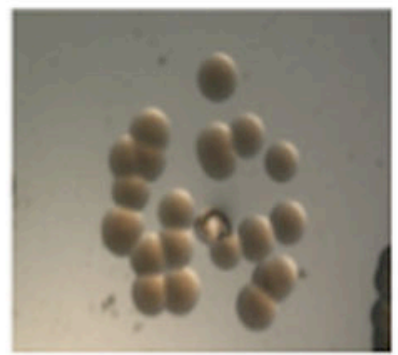

$58 \triangle \mathrm{AB}$ colonies

Horse blood (5\%)

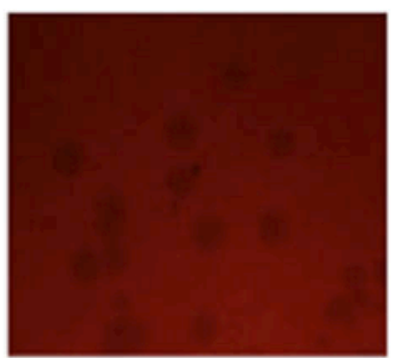

Horse serum + chelex

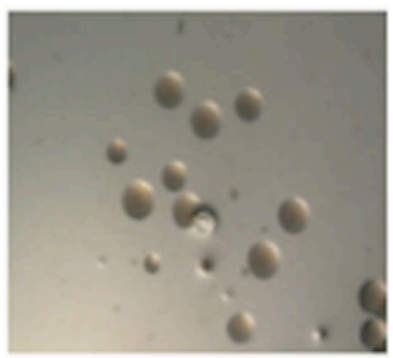

IsoVitalex

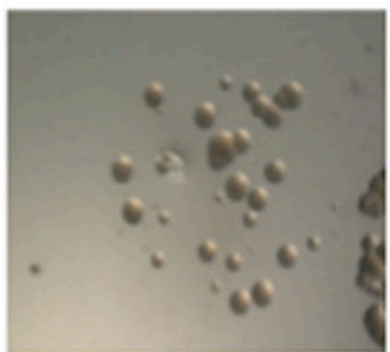

Horse serum (5\%)

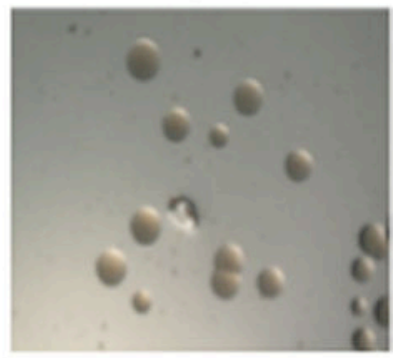

Bovine hemin

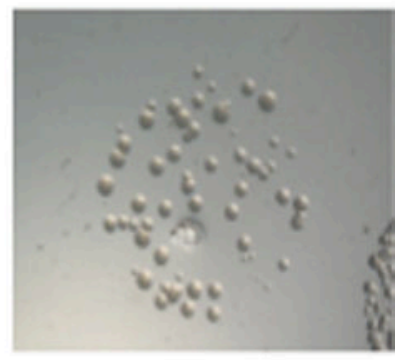

GCB + Kellogg's supps

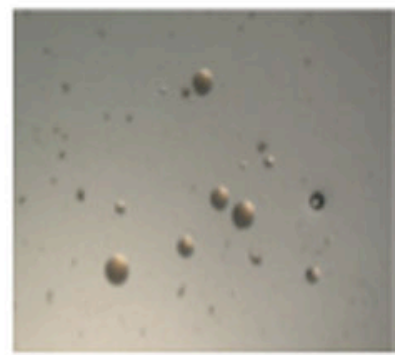

Figure 5.

Growth of $N$. meningitidis $58 \Delta \mathrm{AB}$ on solid media. Bacteria were grown overnight on solid GCB that contained supplementation as indicated, and imaged using a stereoscope. 


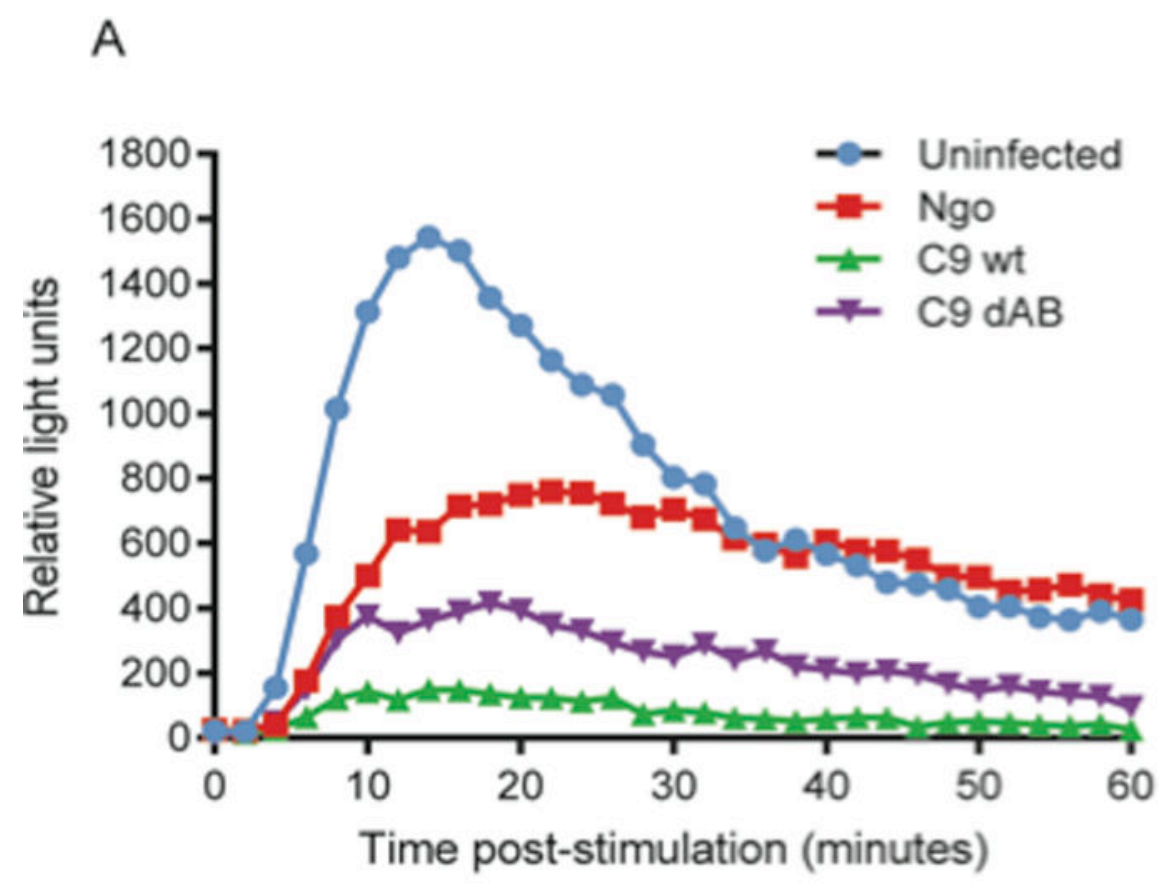

B

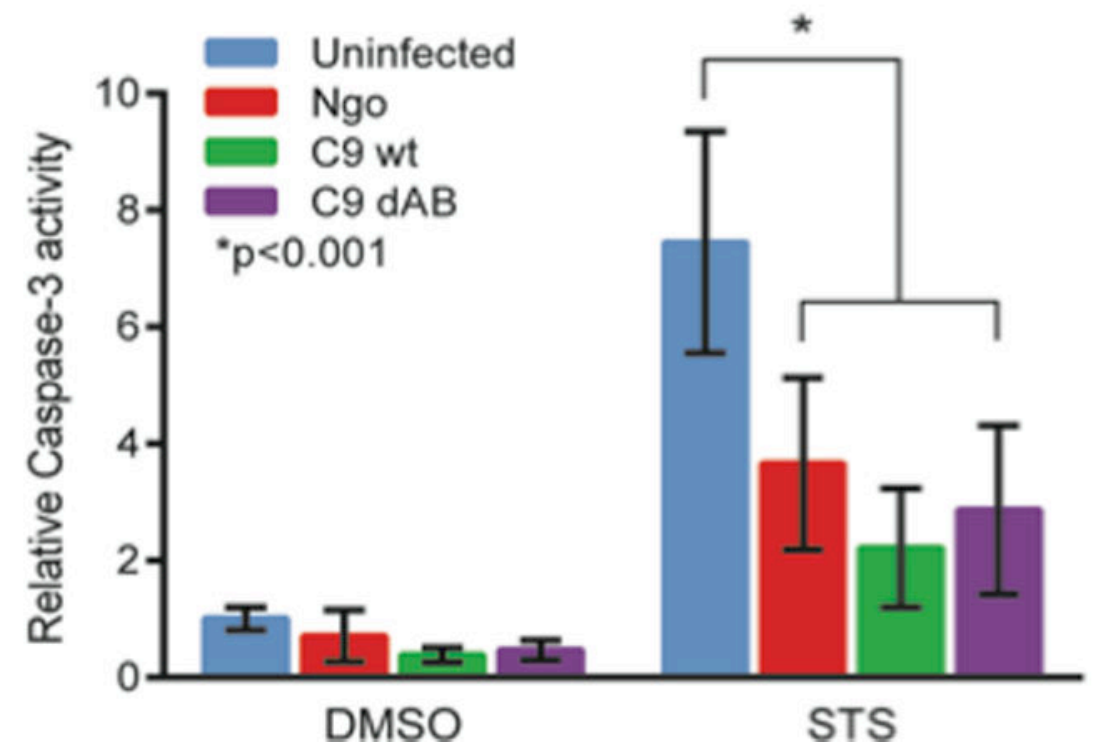

Figure 6.

Effect of porin mutations on (A) the PMA-induced oxidative burst, or (B) staurosporine (STS)-induced caspase-3 activity in differentiated HL-60 cells. Meningococcal strains $\phi 9$ (labelled C9 wt) and $\phi 9 \Delta$ PorAB (labelled C9 dAB) were compared with $N$. gonorrhoeae (labelled Ngo). (A) Differentiated HL-60 cells were stimulated with PMA to induce an oxidative burst and infected with $N$. gonorrhoeae or $N$. meningitidis strains. Luminoldependent chemiluminescence was measured over a period of 60 minutes. (B) Differentiated HL-60 cells were infected with $N$. gonorrhoeae or $N$. meningitidis strains for 3 hours, then 
treated with either STS to induce apoptosis or DMSO as a control for a further 3 hours. Caspase-3 activity was measured using the fluorogenic substrate Ac-DEVD-AMC, and data are presented as the caspase- 3 activity relative to that of uninfected, DMSO-treated controls. 